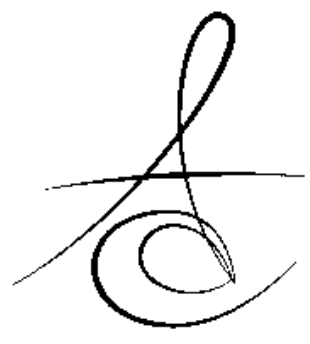

\section{FİBER İLE GÜÇLENDİRME KOMPOZİT REZİNLERİN EĞİLME DİRENCİNE ETKİ EDER Mİ?}

\section{DOES FIBER REINFORCEMENT EFFECT ON FLEXURAL STRENGTH OF COMPOSITE RESINS?}

Yrd. Doç. Dr. Güliz AKTAŞ*
Yrd. Doç. Dr. M.Barış GÜNCü*

Doç. Dr. Emine GÖNCÜ BAŞARAN**

Prof. Dr. Pekka K. VALLITTUU ${ }^{* * *}$

Dr. Lippo V.J. LASSILA**

\author{
Makale Kodu/Article code: 2623 \\ Makale Gönderilme tarihi: 17.02.2016 \\ Kabul Tarihi: $\quad 02.11 .2016$
}

\section{ÖZET}

Amaç: Kompozit rezinler uzun yıllardır hem restoratif dolgu maddesi olarak hem de adeziv restorasyonlarda diş eksikliklerinin giderilmesinde kullanılmaktadır. Artan okluzal yükler karşısında kompozit rezinlerin fiber ile güçlendirilmesi materyalin dayanıklılı̆ını artırmak amacı ile kullanılan bir yöntemdir. Bu invitro çalışmanın amacı fiber ile güçlendirmenin kompozit rezinlerde eğilme direncine olan etkisinin araştırılmasıdır.

Gereç ve Yöntem: Farklı fiber dağılımına ve rezin oranına sahip kompozit bloklar (GR 1, GR 2, GR 3,) ve bir deneysel kompozit (GR 4) laboratuvar ortamında hazırlandı. Fiber ile güçlendirilmiş bloklar ve piyasada yer alan hazır kompozit blok (GR 5) kesme cihazı ile ebadı $2 \times 2 \times 25 \mathrm{~mm}$ olacak şekilde 5 gruba (n:18) ayrıldı. Örneklere 24 saat $37 \mathrm{C}$ de distile suda bekletildikten sonra Universal test cihazında $1 \mathrm{~mm} / \mathrm{dk}$ hızla eğilme testi uygulandı. Sonuçlar tek yönlü varyans analizi (ANOVA) ile değerlendirildi.

Bulgular: Tüm gruplar arasında istatiksel olarak anlamlı farklılık gözlenmiştir $\quad(p<0.001)$. Ortalama eğilme direnci değerleri ve standart sapmaları GR 1 , GR 2, GR 3, GR 4 ve GR 5'de sirasiyla 130 \pm 6 , $125 \pm 5.1,136 \pm 6.8,115 \pm 4$ ve $85 \pm 2.9$ bulundu. Gr 3 en yüksek değeri gösterirken, Gr 5 en düşük değeri göstermiştir $(p<0.001)$.

Sonuç: Bu invitro çalışmada kompozit rezinlerin cam fiber ile güçlendirilmesi eğilme direncini artırmaktadır. Anahtar kelimeler: Kompozit rezin, fiber, eğilme direnci

\section{ABSTRACT}

Aim: Composite resins have been used for many years both as a restorative material and adhesive restorations on the loss of tooth structure. Fiber reinforcement is the most commonly used method for increasing the strength of the composite materials under increased occlusal forces. The aim of this in vitro study was to investigate the effect of fiber reinforcement of composite resins for their flexural strength.

Material and Methods: Composite blocks (GR 1, GR 2, GR 3,) which have different fiber configurations/ resin ratio and experimental composite (GR 4) were prepared in laboratory condition. Fiber reinforced composite blocks and commercial available composite blocks (GR 5) were cut into small specimens (2x2x $25 \mathrm{~mm}$ ) into 5 subgroups $(\mathrm{n}: 18)$. The specimens were stored in distilled water at $37^{0} \mathrm{C}$ for 24 hour, and then flexural strength tests were performed with using Universal Testing Machine. Data were analyzed using one-way ANOVA.

Results: Significant differences were found among the flexural strength of the tested groups $(p<0.001)$. The mean flexural strength values of the GR 1, GR 2, GR 3, GR 4 and GR 5 were 130 $\pm 6,125 \pm 5.1,136 \pm 6.8$, $115 \pm 4$ and $85 \pm 2.9$ respectively. GR 3 exhibited the highest flexural strength values in comparison to the other groups $(p<0.001)$. While control group (Gr 5) exhibited the lowest.

Conclusion: It is concluded that glass fiber reinforcement improves the flexural strength of composite resins.

Key words: Composite resin, fiber, flexural strength

\footnotetext{
Hacettepe Üniversitesi, Diş hekimliği Fakültesi, Protetik Diş Tedavisi, Ankara, Türkiye.

${ }^{* *}$ Dicle Üniversitesi, Diş hekimliği Fakültesi, Protetik Diş Tedavisi Diyarbakır, Türkiye.

*** Turku Üniversitesi, Diş hekimliği Fakültesi, Turku, Finlandiya.
}

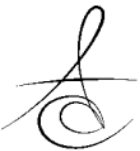




\section{GİRİş}

Kompozit rezinler estetik gereksinimleri karşılamalarının yanı sıra gerekli fiziksel ve mekanik dayanıklıı̆ga sahip olmalıdır. Posterior bölgede hem daimi hem de geçici restorasyonların üretilmesinde uzun yıllardır kullanılmakta olan kompozit rezinlerin statik ve dinamik çiğneme yükleri altındaki mekanik özellikleri son derece önemlidir. Ancak artan okluzal yükler bu tip restorasyonların uzun dönem başarısını olumsuz etkilemektedir. ${ }^{1-3} \mathrm{Bu}$ nedenle kompozit rezinlerin fiziksel özelliklerini geliştirmeye yönelik girişimler devam etmektedir. Kompozit rezinlerin cam fiber ile güçlendirilmesi karbon ve aramid fiberlerle güçlendirilmesine oranla restoratif materyale daha iyi estetik özellik kazandırdığı rapor edilmiştir. ${ }^{4}$ Çok sayıda çalışma fiber ile güçlendirilmiş kompozitlerin dayanıklıIığına etki eden faktörler üzerine yoğunlaşmaktadır. ${ }^{5-8}$ Fiber ile güçlendirmeyi etkileyen birçok faktör bulunmaktadır. Bunlar; kullanılan rezin, fiberlerin boyu ${ }^{9}$ fiberlerin oryantasyonu, fiberlerin pozisyonu ${ }^{10}$ polimer matrikse fiberlerin adezyonu ${ }^{11}$ fiberlerin boyutu ve rezin içerisine fiberlerin emdirilmesi ${ }^{12}$ olarak sıralanabilir. Bu etki eden faktörler içerisinden fiber pozisyonu ve dağılımı, materyalin mekanik özelliklerini etkilemektedir. Dolayısı ile kompozit rezinler belirli yapısal karakteristik özellikte olmaları için dizayn edilebilir. Kompozit rezin üretici firmalar, materyalin içerisindeki fiber oryantasyonunu, miktarını ve geometrisini değiştirerek materyalin arzu edilen özelliklerini düzenleyebilirler. ${ }^{13}$ Fiber ile güçlendirilmiş kompozitlerin geliştirilmesi, diş dokusunun kaybında klinisyenlerin adeziv, estetik ve metal içermeyen geçici ve daimi restorasyonları üretmelerine olanak sağlamıştır. Aynı zamanda fiber ile güçlendirilmiş kompozit rezinler hekim açısından da bazı avantajlara sahiptir. Yapılması gereken işlem tek seansta hasta başında hızlı bir şekilde yapılabilir ve herhangi bir başarısızlık durumunda tamir edilmesi kolaydır. ${ }^{14} \mathrm{Bu}$ invitro çalışmanın sıfır hipotezi, fiber ile güçlendirilen ve güçlendirilmeyen kompozit rezinlerin eğilme dirençleri arasında fark olmamasıdır.

\section{GEREÇ VE YÖNTEM}

Farklı fiber dağılımına ve rezin oranına sahip kompozit bloklar laboratuvar ortamında hazırlandı. Bloklar kendi aralarında 5 gruba ayrıldı. Bunlar üç tane fiberle güçlendirilmiş deneysel kompozitten yapılmış blok, bir tane deneysel kompozitten yapılmış blok ve bir tane de piyasada hazır olarak bulunan prefabrike bloktan oluşmaktadır. hazırlandı.

Çalışmadaki gruplar aşağıdaki şekilde

Deneysel devamlı tek yönlü (unidirectiona) fiberlerle güçlendirilmiş kompozitin hazırlanması (Gr 1): $\% 35 \mathrm{BaOSiO}_{2}$ (1\% silan, $0.7 \mu \mathrm{m}$ büyüklüğünde cam partikülleri) ile \%35 dimetakrilat-PMMA rezin yüksek hızlı santrifüjlü karıştırma aletinde $5 \mathrm{dk}$. süre karıştırıldı. Daha sonra \%30 tek yönlü cam fiber (EverStick; Stick Tech Ltd., Turku, Finland) bu karışımla doyuruldu.

Deneysel devamlı çift yönlü (bidirectiona) fiberlerle güçlendirilmiş kompozitin hazırlanması (Gr 2): \%38 $\mathrm{BaOSiO}_{2}$ (1\% silan, $0.7 \mu \mathrm{m}$ büyüklüğünde cam partikülleri) ile \%38 dimetakrilat-PMMA rezin yüksek hızlı santrifüjlü karıştırma aletinde $5 \mathrm{dk}$ süre karıştırıldı. Daha sonra \%24 çift yönlü cam fiber (Sticknet; Stick Tech Ltd.) bu karışımla doyuruldu.

Deneysel rastgele dağılımlı (randomly orientated) fiberlerle güçlendirilmiş kompozitin hazırlanması (Gr 3): \%28.5 cam fiber (10 mm uzunluğunda), \%26.5 dimetakrilat-PMMA rezinle karıştırıldıktan sonra, \%45 $\mathrm{BaOSiO}_{2}$ (1\% silan, $0.7 \mu \mathrm{m}$ büyüklüğünde cam partikülleri) doldurucu partiküllerin ilavesiyle homojen bir yapı oluşturulmasıyla elde edildi.

Deneysel kompozitin hazırlanması ( $\mathrm{Gr} 4$ ): \%25.6 dimethacrylate-PMMA rezin matriks ile \% 74.3 $\mathrm{BaOSiO}_{2}$ (1\% silane, $0.7 \mu \mathrm{m}$ büyüklüğünde cam partikülleri) doldurucu partiküllerin yüksek hızlı santrifüjlü karıştırma aleti $5 \mathrm{dk}$ süre karıştırılmasıyla hazırlandı.

Hazır blok (Vita CAD-Temp;Vita Zahnfabrik, Sackingen, Germany) (Gr 5).

Fiber ile güçlendirilmiş kompozit rezin blokların üretiminde silikon kalıp kullanıldı. Rezin kompozitler silikon kalıp içerisine yerleştirildi ve 1 saat vakum altında ısıl işlem ile polimerizasyon cihazında (Ivoclar AC, Schaan, Liechtenstein) sertleştirildi.

Elde edilen fiberle güçlendirilmiş kompozit rezin bloklar ve Vita CAD Temp blok, kesme cihazında $2 \times 2 \times 25 \mathrm{~mm}$ boyutunda küçük çubuklar şekline getirildi. Toplamda 90 tane örnek elde edildi. Kesme işlemi sonrasında elde edilen örneklerin boyutları dijital kalınlık ölçer (EC 08; Tresna Instrument Co Ltd, Guilin, China) kullanılarak ölçüldü. Örnekler 24 saat $37^{\circ} \mathrm{C}$ de distile suda bekletildikten sonra Universal test cihazında (Model LRX; Lloyd Instruments Ltd, Fareham, UK) $1 \mathrm{~mm} / \mathrm{dk}$ hızla üç nokta eğilme testine tabi tutuldu. Önceden dijital mikro-metre ile orta

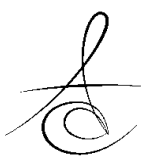


noktası tespit edilmiş olan örneklerin, tam ortasına $90^{\circ}$ gelecek şekilde kuvvet uygulandı. Örneklerde kırılma kayıt edilene kadar yükleme yapıldı. Örneklerde kırılmaya neden olan maksimum kuvvet değerleri belirlendi. Veriler uygun yazılım (Nexygen; Lloyd Instruments Ltd) kullanılarak kayıt edildi.

Her gruptan bir örnek yüzey morfolojisi ve fiber dağıımın incelenmesi için 4000 gritlik aşındırıcı kağıtlar (Federation of European Producers of Abrasives [FEPA]) ile kuru aşındırıldı ve karbon ile kaplandiktan sonra (SCD 050; Bal-Tec, Balzers, Liechtenstein) taramalı elektron mikroskobunda (SEM) (JSM5500; JEOL, Tokyo, Japan) görüntülendi (Şekil 1). Tek yönlü varyans analizi (ANOVA) ve Tukey post hoc çoklu karşılaştırma testi, gruplar arasında istatiksel olarak anlamlı farkılık olup olmadığını belirlemek için kullanıldı.

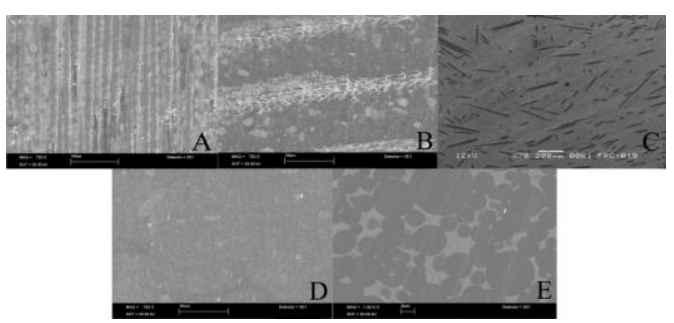

Şekil 1. Herbir gruptan bir örneğin SEM görüntüsü; A: Gr 1 , B: Gr 2, C: Gr 3, D: Gr 4, E: Gr 5.

\section{BULGULAR}

Örneklerin kırılma değerleri, standart deviasyonları, standart sapmaları, maksimum ve minimum değerleri Tablo 1 da verilmiştir. İstatiksel analiz kırılma değerlerine göre hesaplanmıştır. Tek yönlü varyans analizi ANOVA tüm gruplar arasında istatiksel olarak anlamlı farklılık olduğunu göstermiştir $\quad(P<.001)$ Tukey post hoc çoklu karşılaştırma testi gruplar arasındaki farklııkları belirlemek için kullanıldı. Gr 3 en yüksek değeri gösterirken, Gr 3-Gr 1, Gr1-Gr2 arasında fark görülmedi. Gr 5 en düşük değeri gösterdi.

Tablo1. Grupların istatistiksel analiz sonuçları

\begin{tabular}{|c|c|c|c|c|c|c|c|}
\hline Gruplar & $\begin{array}{c}\text { Ortalama } \\
\text { değerler (MPa) }\end{array}$ & Sd & Ss & Maksimum & Minimum & $\mathbf{F}$ & $p$ \\
\hline Gr 1 & 130 & 9.8 & 5.0 & 150 & 110 & \multirow{5}{*}{17.436} & \multirow{5}{*}{0.001} \\
\hline Gr 2 & 125 & 0.2 & 5.1 & 146 & 105 & & \\
\hline Gr 3 & 136 & 0.1 & 5.8 & 152 & 109 & & \\
\hline Gr 4 & 115 & 9.4 & 4.0 & 130 & 97 & & \\
\hline Gr 5 & 85 & 6.1 & 2.9 & 95 & 78 & & \\
\hline
\end{tabular}

\section{TARTIŞMA}

$\mathrm{Bu}$ invitro çalışmada farklı yönlerdeki fiberler ile güçlendirilen ve güçlendirilmeyen kompozit rezinlerin eğilme dirençleri incelenmiş olup sıfır hipotezi reddedilmiştir.

Son zamanlarda çok sayıda klinik rapor fiber ile güçlendirilmiş kompozit rezinlerin farklı kullanım alanlarını göstermektedir. Bunların başında periodontal mobilite kontrolü için anterior dişlerin splintlenmesi, sabit bölümlü protezlerde dayanak ve gövde olarak kullanımı, invaziv olmayan yöntemlerle yer tutucu olarak kullanımı sıralanabilir. ${ }^{15,16}$ Bu klinik çalışmalara ilave olarak kompozit rezinlerin klinik başarısını öngörebilmek amacı ile bir çok invitro çalışma literatürde yer almaktadır. ${ }^{17-20}$ Materyal seçimi restorasyonun klinik başarısında son derece önemlidir. Kompozit restorasyonlarda görülen kırık ya da çatlak restorasyonun uzun dönem başarısını olumsuz etkilemektedir. Restorasyonlarda gerçekleşen kırılma ya da çatlamanın engellenmesi için direncinin artırılması gerekir. Özellikle kompozit rezinlerin fiber ile güçlendirilmesi eğilme dayanıkılığını olumlu yönde etkilemektedir. Doğru şekilde yerleştirilmiş ve düzenlenmiş fiberler ilave edildikleri kompozit rezinin eğilme dayanıkıı̆ı̆ını artırmaktadır. Doldurucu kompozisyonu, doldurucu büyüklüğü, ağırlıkça oranı, morfolojisi ve dağılımı aynı zamanda rezinin sertlik ve viskozitesine etki etmektedir. ${ }^{21}$ Dayanıklılıktaki artış, stresin kompozit rezinin zayıf olan kısmı matriksten yüksek gerilme dayanıklılığına sahip olan fibere aktarılması ile açıklanabilir. Fiber ile matriks arasındaki bağlantı ne kadar kuvvetli olursa fiberin kompozit rezini güçlendirme miktarı da o kadar fazla olmaktadır. Fiber ile güçlendirilmiş kompozitler tek başlarına değil aynı zamanda kompozit rezin altında bir alt yapı olarak da kullanılabilmektedir. Fiberle güçlendirilmiş kompozit altyapılar kompozit rezin tabakasını destekler ve oluşan herhangi bir çatlağın ilerlemesini yavaşlatır veya durdurur. Buna ilave olarak fiberle güçlendirme yıkıcı ve aniden oluşan kırılmaları da en aza indirir. ${ }^{22}$ Fiberlerin pozisyonu ve yönü restorasyonun güçlendirilmesinde etkili bir faktördür. ${ }^{23,}{ }^{24}$ Tek yönlü fiberler anizotropik bir davranış gösterirken çok yönlü fiberler ortotropik, rastgele dağılımlı fiberler ise izotropik özelliktedir. ${ }^{25,} 26$ Jones ve ark. porozitenin eğilme dayanıkılığı ve kırılmaya karşı direnç gibi materyalin mekanik özelliklerini azalttığını ve bunun 
sonucunda da rezin ile doldurucu arasında tam gerçekleşmeyen mikro mekanik bağlantı oluştuğunu bildirmiştir. ${ }^{27}$ Bu çalışmada kullanılan karıştırma aleti (speed mixer), örneklerin ISı ve basınç altında polimerize edilmesi ile kompozit rezin içerisindeki pörözite en az miktara indirilmeye çalışılmıştır.

Önceki çalışmalar fiberle güçlendirilmiş kompozit restorasyonların, fiberle güçlendirilmemiş restorasyonlardan daha yüksek kırılma direncine sahip olduğunu rapor etmişlerdir. ${ }^{25,}{ }^{26} \mathrm{Bu}$ invitro çalışma da literatürde yer alan önceki çalışmalar ile benzer olarak fiberle güçlendirmenin kırılma direnci üzerinde arttırıcı bir etkisi olduğu göstermektedir. Fiberle güçlendirilmiş tüm gruplar kompozit gruplara göre yüksek değerler göstermiştir. Krenchel faktörüne göre tek yönlü güçlendirmenin iki yönlü güçlendirmeye göre daha etkili olduğu bildirilmektedir. Bu invitro çalışmada da tek yönlü fiber (Grup 1) ile güçlendirilen gruptaki örneklerin eğilme dayanım direnci çift yönlü fiber (Grup 2) ile güçlendirilen gruptaki örneklerden daha yüksek olmasına rağmen aradaki fark istatistiksel olarak anlamlı bulunmamıştır. Geleneksel kompozit blok en düşük kırılma direncini gösterirken deneysel olarak hazırlanan kompozit daha yüksek değerlerde kırılmıştır. SEM görüntülerinde izlendiği gibi deneysel kompozit, geleneksel kompozit bloğa göre daha homojen bir yapı sergilemektedir. Bu durum eğilme direncine katkı sağlamış olabilir. Buna ilave olarak SEM görüntülerinde tüm fiberle güçlendirilmiş gruplarda fiber ile rezin arasında çok iyi bir penetrasyon izlenmektedir.

Fiberle güçlendirilmiş kompozit restorasyonlarda fiber miktarının artması eğilme direnci üzerinde pozitif bir etki oluşturmaktadır. Benzer şekilde yüksek fiber oranına sahip Gr 1 ve Gr 3 birbirine benzer ve daha yüksek sonuçlar göstermiştir. Yüksek doldurucu oranı ve izotropik yapı Gr 3 ün eğilme direncine olumlu etkili etmiş olabilir.

\section{SONUÇ}

Fiberle güçlendirme genel olarak kompozit rezinlerin eğilme direncini artırmıştır. Bu olumlu sonuçlara rağmen fiberle güçlendirilmiş kompozitlerle ilgili daha çok ve uzun takipli çalışma sonuçlarına ihtiyaç vardır.

\section{KAYNAKLAR}

1. Gaengler P, Hoyer I, Montag R, Gaebler P. Micromorphological evaluation of posterior composite restorations - a 10-year report. J Oral Rehabil 2004;31:991-1000.

2. Kohler B, Rasmusson CG, Odman P. A five-year clinical evaluation of Class II composite resin restorations. J Dent 2000;28:111-6.

3. Sarrett DC. Clinical challenges and the relevance of materials testing for posterior composite restorations. Dent Mater 2005;21:9-20.

4. Vallittu PK, Narva K. Impact strength of a modified continuous glass fiber - Poly(methyl methacrylate). Int J Prosthodont 1997;10:142-8.

5. Kangasniemi I, Vallittu P, Meiers J, Dyer SR, Rosentritt M. Consensus statement on fiberreinforced polymers: Current status, future directions, and how they can be used to enhance dental care. Int J Prosthodont 2003;16:209-9.

6. Kim SH, Watts DC. Effect of glass-fiber reinforcement and water storage on fracture toughness (K-JC) of polymer-based provisional crown and FPD materials. Int J Prosthodont 2004;17:318-22.

7. Vallittu PK. Flexural properties of acrylic resin polymers reinforced with unidirectional and woven glass fibers. J Prosthet Dent 1999; 81: 318-26.

8. Vallittu PK. Survival rates of resin-bonded, glass fiber-reinforced composite fixed partial dentures with a mean follow-up of 42 months: A pilot study. J Prosthet Dent 2004;91:241-6.

9. Stipho HD. Repair of acrylic resin denture base reinforced with glass fiber. J Prosthet Dent 1998;80:546-50.

10. Dyer SR, Lassila LVJ, Jokinen M, Vallittu PK. Effect of fiber position and orientation on fracture load of fiber-reinforced composite. Dent Mater 2004;20:947-55.

11. Vallittu PK. The Effect of Void Space and Polymerization Time on Transverse Strength of Acrylic-Glass Fiber-Composite. J Oral Rehabil 1995;22:257-61.

12. Miettinen VM, Vallittu PK. Water sorption and solubility of glass fiber-reinforced denture polymethyl methacrylate resin. J Prosthet Dent 1997;77:531-4.

13. Barbero EJ. Introduction to composite material design: 2nd ed. Taylor and Francis:2010.p.27-59.

14. Arhun N, A A. Fiber-reinforced technology in multidisciplinary chairside approaches. Indian J Dent Res 2008;19:272-7. 
15. Bagis B, Satiroglu I, Korkmaz FM, Ates SM. Rehabilitation of an extracted anterior tooth space using fiber-reinforced composite and the natural tooth. Dent Traumatol 2010;26:191-4.

16. Tayab T, Vizhi K, Srinivasan I. Space maintainer using fiber-reinforced composite and natural tootha non-invasive technique. Dent Traumatol 2011;27:159-62.

17. Bijelic-Donova J, Garoushi S, Vallittu PK, LV. L. Mechanical properties, fracture resistance, and fatigue limits of short fiber reinforced dental composite resin. J Prosthet Dent 2016;115:95-102.

18. Garoushi S, Sailynoja E, Vallittu PK, Lassila L. Physical properties and depth of cure of a new short fiber reinforced composite. Dent Mater 2013;29:835-41.

19. Kamble VD, Parkhedkar RD, Mowade TK. The effect of different fiber reinforcements on flexural strength of provisional restorative resins: an invitro study. J Adv Prosthodont 2012;4:1-6.

20. Candan U ， Eronat E ， Turkun M . Fiberle güçlendirmenin nanofil kompozitin eğme direncine etkisinin incelenmesi . Atatürk Üniv Diş Hek Fak Derg 2015;25:13-20.

21. Venhoven BAM, deGee AJ, Werner A, Davidson CL. Influence of filler parameters on the mechanical coherence of dental restorative resin composites. Biomaterials 1996;17:735-40.

22. Ellakwa AE, Shortall AC, Shehata MK, Marquis PM. The influence of fibre placement and position on the efficiency of reinforcement of fibre reinforced composite bridgework. J Oral Rehabil 2001;28:785-91.

23. Altieri JV, Burstone CJ, Goldberg AJ, Patel AP. Longitudinal Clinical-Evaluation of Fiber-Reinforced Composite Fixed Partial Dentures - a Pilot-Study. J Prosthet Dent 1994;71:16-22.

24. Vallittu P. Glass fiber reinforcement in repaired acrylic resin removable dentures: preliminary results of a clinical study. Quintessence Int 1997;28:39-44.

25. Basaran EG, Ayna E, Vallittu PK, Lassila LVJ. Load Bearing Capacity of Fiber-Reinforced and Unreinforced Composite Resin Cad/Cam-Fabricated Fixed Dental Prostheses. J Prosthet Dent 2013;109:88-94.
26. Keulemans F, Lassila LVJ, Garoushi S, et al. The influence of framework design on the load-bearing capacity of laboratory-made inlay-retained fibrereinforced composite fixed dental prostheses. J Biomech 2009;42:844-9.

27. Jones M, Bayne SC, Thompson JY. Effects of branched-fiber pillar additions on dental composite mechanical properties. J Dent Res 1997;76:76.

\author{
Yazışma Adresi \\ Güliz Aktaş \\ Hacettepe Üniversitesi Diş Hekimliği Fakültesi \\ Protetik Diş Tedavisi A.D. \\ 06100 Sinhiye /Ankara \\ Tel: +90 3123052240 \\ Fax: +90 3123113741 \\ E-mail: dtgulizaktas@gmail.com
}

